\title{
Role of Dietary and Lifestyle Modifications in the Secondary Prevention of Biomarkers of Plaque recurrence in Omani Coronary Revascularized Patients
}

\author{
Amanat Ali ${ }^{1,2, *}$, Noura S.M. Al-Alawi ${ }^{2}$, Muhammad Athar Sadiq ${ }^{3}$ and Mostafa I. Waly ${ }^{2}$ \\ ${ }^{1}$ School of Engineering, University of Guelph, Albert A. Thornbrough Building, 50 Stone Road East, Guelph, \\ Ontario, N1G 2W1, Canada \\ ${ }^{2}$ Department of Food Science and Nutrition, College of Agricultural and Marine Sciences, Sultan Qaboos \\ University, P.O. Box 34, Al-Khoud 123, Muscat, Oman \\ ${ }^{3}$ Cardiology Unit, Department of Medicine, College of Medicine and Health Sciences, Sultan Qaboos \\ University, Al-Khoud 123, Muscat, Oman
}

\begin{abstract}
Objective: To assess the role of various dietary and lifestyle modifications in the secondary prevention of biomarkers of plaque recurrence in Omani coronary revascularized patients.

Methods: Seventy-two patients, from the outpatient cardiology clinic of Sultan Qaboos University Hospital, were included in the study after obtaining an informed consent. In a questionnaire-based study, we collected data about four lifestyle modifications; physical activity, weight reduction, dietary intake and healthy eating patterns and smoking or non-smoking status, in personal interviews. A modified previously validated study questionnaire, which comprised of a semiquantitative food frequency questionnaire, was used to assess the demographic information, eating patterns, diet quality index score, and daily dietary intake of study participants. The data about patient's baseline characteristics, revascularization information and biochemical laboratory tests was harvested from the SQUH's electronic record system. The statistical analysis of data was made using R-studio v.7 and Microsoft excel v.7.

Results: The males had higher educational level as compared to females and were more active than females. The data indicated that $16 \%$ males and females were diabetic, $10 \%$ males and $21 \%$ females were hypertensive, and $30 \%$ males and $42 \%$ females had both diabetes and hypertension. Forty eight percent males and $63 \%$ females had body mass index $(\mathrm{BMI})>30$. However, no significant $(P<0.05)$ differences were observed in the $\mathrm{BMI}$, diabetes and hypertension status in males and females. Both genders had poor nutritional knowledge. Although the LDL-C and HDL-C values in males and females differed, they were within the normal therapeutic limits. The $\mathrm{HbA} 1 \mathrm{c}$ and $\mathrm{C}$-reactive protein values were above the normal ranges with no significant $(P<0.05)$ difference in both males and females. The average daily energy intake in males (2694 kcalories) was significantly higher compared to females (1603 kcalories). The proportionate contribution of energy from macronutrients was within the acceptable macronutrient distribution ranges. Omani diet score for males (75.5) and females (74.6) didn't differ significantly $(P<0.05)$, indicating their adherence to healthy dietary patterns

Conclusions: The results suggest that dietary and lifestyle modifications play significant role in the secondary prevention of biomarkers of plaque recurrence in Omani coronary revascularized patients. Behavioral counseling to promote healthy modifications in dietary and lifestyle factors are therefore recommended in the secondary prevention of risk of plaque recurrence.
\end{abstract}

Keywords: Dietary and lifestyle modifications, Secondary prevention, Plaque recurrence, Omani coronary revascularized patients.

\section{INTRODUCTION}

Cardiovascular diseases (CVDs) are the leading cause of global mortality and morbidity and represent $31 \%$ of all global death $[1,2]$. In the Middle East countries, the CVDs-associated mortality rate is higher than the world [3]. The hospital deaths due to coronary heart diseases (CHD) in Oman have gone up in the past years, which has been associated with the poor knowledge about the risk factors of CHDs [4]. It has

*Address correspondence to this author at the School of Engineering, University of Guelph, Albert A. Thornbrough Building, 50 Stone Road East, Guelph, Ontario, N1G 2W1, Canada; Tel: +1-519-824-4120 Ext: 53499; Fax: +1-519-836-0227; E-mail: amanat@uoguelph.ca, amanata@gmail.com been shown that the Middle Eastern patients, with acute coronary syndrome (ACS) had heart attacks at relatively younger age as compared to patients in Western countries [5, 6]. There are numerous biomarkers for the diagnostic, prognostic and prediction of CVDs [7]. The main inflammatory biomarkers, which predict the severity and prognosis of heart failure are high-sensitive C-reactive protein (hs-CRP), cytokines, tumor necrosis factor alpha (TNFa), interleukins (IL-1, IL-6 etc.), adiponectin and $\mathrm{N}$-terminal probrain natriuretic peptide [8]. It has been reported that overall aggregate incidence of CVDs in tye-2 diabetic Omani patients is $9.4 \%$ [9], whereas $54.1 \%$ had diabetes at the time of coronary artery bypass surgery [10].

(C) 2020 SET Publisher 
Diabetic cardiovascular patients with insulin resistance showed higher concentrations of hs-CRP and IL- 6 as compared to non-insulin resistance patients during secondary prevention of CVDs, which was associated with their saturated fatty acids intake [11]. The main reasons associated with CVDs in Omani population are overweight, obesity, dyslipidemia, hypertension, diabetes mellitus, smoking, sedentary lifestyle, male gender and family history of heart diseases [4, 12, 13]. More than $87 \%$ of Omanis had $\geq 3$ of these risk factors at the time of coronary artery bypass grafting [10]. According to a recent survey $10 \%$ of youth (13-15 years) use tobacco and another $12 \%$ are affected by passive smoking. Around $84 \%$ of the adolescents have insufficient physical activity [14].

Primary, secondary, and tertiary prevention strategies are applied to prevent, control and manage the CVDs at various levels. Pharmacological interventions, at primary and secondary prevention levels. can considerably reduce the risk of cardiovascular events and mortality $[15,16]$. Just a $10 \%$ decrease in LDL-cholesterol level can lower the cardiovascular mortality and events by 10 and $25 \%$, respectively [17]. The new American College of Cardiology (ACC) guidelines recommend $\geq 50 \%$ reduction in LDL-C levels in all patients with established coronary artery disease [18]. The data indicates that the efficacy of pharmacological treatment such as statins can be improved by diet and lifestyle modifications $[19,20]$. Statin therapy together with smoking cessation might have a beneficial effect in reducing the malondialdehyde-modified low-density lipoprotein (MDA-LDL) levels [21]. It has been suggested that even a modest reduction in LDL-C level might offer significant mortality benefits in the long-term $[22,23]$.

Healthy dietary patterns and physical activity lower weight gain, inflammation, blood pressure, metabolic syndrome risk factors, clinically improve the LDL-C levels, and overall contribute to positive cardiometabolic outcomes [24-27]. The intensive modifications of dietary and lifestyle risk factors showed positive impact in the secondary prevention of cardiovascular incidents, both in normal and diabetic patients [28]. Young to middle-aged adults, particularly males with newly diagnosed obstructive coronary artery disease, having high body mass index (BMI) and smoking habits, showed higher association with lifestyle and traditional CVDs risk factors with the development of CVDs [29]. It has, however, been observed that the people don't follow the healthy diet plans even after the occurrence of first stroke. Many readmissions could be avoided if the cardiac patients adhere to dietary and lifestyle modifications such as healthy dietary patterns, physical activity and smoking cessation [30]. Behavioural improvements in cardiac patients through education on healthy lifestyle and dietary patterns are therefore important in the secondary prevention of cardiovascular incidents. It is assumed that major threat to death and disability due to cardiovascular diseases (CVDs) in Oman may be ascribed to unhealthy eating patterns and sedentary lifestyle risk factors. In addition to this, the neighborhood environment traits such as high residential density, poor walkability, presence of increased number of fast food restaurants and supermarkets are linked to increased body mass index, blood pressure, diabetes mellitus and metabolic syndrome and confirm positive association with CVDs outcomes [31]. Unhealthy eating habits, sedentary lifestyle, lack of physical activity and smoking are the key modifiable risk factors and targeting them can significantly contribute in the prevention of CVDs at primary and secondary levels [15]. Dietary and lifestyle modifications proved to be effective in the primary prevention of CVDs [32], however, only limited data is available about their effectiveness in the secondary prevention of CVDs, particularly in post coronary artery bypass grafting (CABG) or percutaneous coronary intervention ( $\mathrm{PCl})$ Omani patients [13, 33-35]. This study is conducted to evaluate the impact of dietary and lifestyle modifications on the efficacy of lowering the LDL-C levels and other biomarkers of plaque recurrence and to assess their effectiveness in the secondary prevention of CVDs in Omani revascularized patients, who have undergone $\mathrm{CABG}$ or $\mathrm{PCl}$.

\section{METHODS}

It is a questionnaire-based study, which evaluated the four lifestyle modifications measures; physical activity, weight reduction, healthy eating patterns and smoking behaviour. Seventy-two cardiac patients (both male and females, average age (63 \pm 6 years) with a previous history of $\mathrm{PCl}$ or bypass surgery were recruited on voluntary basics from Outpatient Cardiology Clinic of Sultan Qaboos University Hospital (SQUH). The patients, who disrupted their statin therapy for a period of $\geq 3$ months and those with severe illness, which may stop their mobility were barred from the study. All the volunteers were briefed about the study protocol and an informed signed consent was obtained. The ethical approval of the study was obtained from the Medical Ethics Committee 
of College of Medicine and Health Sciences, Sultan Qaboos University (Reference No. SQU-EC/250/17; MREC \# 1629).

A previously validated study questionnaire, which comprised a semi-quantitative food frequency questionnaire [36], was modified to meet this study's requirements and was used for the assessment of demographic information, lifestyle factors, dietary intake patterns, and diet quality index score. The information was collected through personal interviews of patients. Patient's baseline characteristics, revascularization information and biochemical lab-tests data was harvested from the SQUH's electronic record system. The variables related to sociodemographic characteristics and CVDs risk factors included age, gender, level of education, type of work, date of coronary procedure, medical history of diabetes and hypertension, physical activity, smoking, multivitamin and mineral supplement intake and nutrition knowledge. The data about the anthropometric measurements (height in meters $(\mathrm{m})$ and weight in kilograms (kg)) was harvested from the SQUH's electronic health record system to calculate the body mass index (BMI) as the weight $(\mathrm{kg})$ divided by height $\left(m^{2}\right)$.

A previously tested and validated food frequency questionnaire (FFQ) that included the traditional Omani foods was used to assess the daily intake of total calories, protein, carbohydrates, and fats. Specific portion sizes and measures using common serving units/utensils like teaspoon, tablespoon, $240 \mathrm{ml}$ cup and $180 \mathrm{ml}$ cup were applied. The study questionnaire also included questions related to dietary intake patterns to know how frequently and in what quantity certain foods are consumed such as either never, a few times a year, 1-2 times in a month, 1-2 times in a week, 3-4 times per week, 5-6 times per a week, once daily, 1-3 times per day or 4-5 times a day. Based on this information, the daily amount of food consumed during the previous year was calculated. The data was collected for a total of 45 commonly consumed Omani food items from different food groups that generally contribute to the nutrient and energy intake by the population. The food groups included were breads/cereals, meat and meat substitutions, fruits, vegetables, legumes and nuts, milk and dairy products, deserts, beverages, sandwiches, and traditional Omani foods. There were several options for any question and the researcher selected the best choice given by the patient [36]. The data collected by the FFQ was analyzed and total daily energy, protein, carbohydrate and fat intakes were calculated based on the nutrient estimates given to each food item in the FFQ. The estimation of macronutrients and total calorie intake was done either through Food Tracker (a computerbased nutrient analysis program) or based on the data generated from our own laboratory about the chemical composition of Omani foods. Macronutrients (g) and total energy (kcal) intake were calculated after measuring the daily amount of each food consumed. The macronutrients were estimated for each unit $(\mathrm{g})$ of food item. Finally, the daily intake of energy and macronutrients was estimated from that food item by multiplying the corresponding content of each macronutrient and energy. The calculations were done by Microsoft excel sheet with required equations.

For the first time, we developed and introduced an Omani Diet Score that was based on 25 dietary assessment questions related to dietary intake patterns and food habits of Omani population. It was used to measure not only the diet quality but also how healthy the participant's dietary intake patterns and food habits were and how much they adhere to the recommended dietary guidelines. It represents the measurement of diet quality based on the Recommended Dietary Allowance (RDA), Healthy Eating Index (HEI) and Alternative Healthy Eating Index (AHEI) guidelines to reduce the risk of non-communicable diseases [37, 38]. It characterizes how the Omani diet conforms to the recommendations for the consumption of various foods for the supply of protein, carbohydrates, fat, vitamins and minerals, and is compatible to the dietary guidelines on fat, cholesterol, and sodium intake, and diet variety. It also includes dietary intake patterns, which are linked to reduced risk of chronic diseases. The study subjects answered how often they stick to these factors and the scores were given accordingly for the 4 options; Always: occurs 7 days per week (4 points); Often: occurs 4-5 days per week (3 points); Sometimes: occurs 1-2 days per week (2 points); Never: does not occur (1 point). The total score was calculated as 100 . The higher score indicates healthier dietary patterns, and is linked to decreased risk of CVDs and other chronic diseases [37]. The data was classified into categories according to public health guidelines to facilitate the interpretation of the results. The statistical analysis of data was carried out by $R$ studio version 7 and Microsoft Excel version 7 . Unpaired t-test was used to examine the level of significant difference between various parameters. The level of significance in educational level, smoking and physical activity between males and females was analyzed using Fisher's test followed by Chi $\left(x^{2}\right)$. One- 
way analysis of variance (ANOVA) followed by Turkey's test was used to determine differences in BMI among males and females. Similarly, the significant differences in the biochemical parameters were analyzed using $t$-test. The level of significance was set at $P<0.05$.

\section{RESULTS}

The general characteristics of the study participants are given in Table 1. The data shows that only $16 \%$ males and $12 \%$ females had primary education, $24 \%$ males and $4 \%$ females had general diploma, $16 \%$ males and $4 \%$ females had higher diploma and only $10 \%$ males and $4 \%$ females had university degree. Males had significantly $(P<0.05)$ better educational level as compared to females. The body mass index of the participants ranged from 20.5 to $38.3 \mathrm{~kg} / \mathrm{m}^{2}$ in males and 21 to $37 \mathrm{~kg} / \mathrm{m}^{2}$ among females and didn't differ significantly $(P>0.05)$ between genders. Significantly more males were in the overweight category $(42 \%)$, whereas more women $(55.6 \%)$ were in the obese category. Most of the cardiac patients were either diabetic, hypertensive or both diabetic and hypertensive (Figure 1). More female participants $(42 \%)$ were hypertensive and diabetic, whereas higher percentage of males (44\%) had neither diabetes nor hypertension. Smoking wasn't common in participants as only $2.4 \%$ of males were smokers and $8 \%$ of them quitted smoking after their surgeries and the remaining percentages were non-smokers. It is was interesting to note that all females were non-smokers. The physical activity level among males and females differed

Table 1: General Characteristics of the Study Participants

\begin{tabular}{|c|c|c|c|}
\hline Sociodemographic Characteristics & Male $n=41$ & Female $n=31$ & Level of significance \\
\hline \multicolumn{4}{|l|}{ Education level: } \\
\hline less than primary & $34 \%$ & $76 \%$ & \multirow{5}{*}{$<0.05$} \\
\hline primary & $16 \%$ & $12 \%$ & \\
\hline general diploma & $24 \%$ & $4 \%$ & \\
\hline higher diploma & $16 \%$ & $4 \%$ & \\
\hline university degree & $10 \%$ & $4 \%$ & \\
\hline \multicolumn{4}{|l|}{ BMI: } \\
\hline $18-24.9$ (normal weight) & $9.70 \%$ & $22 \%$ & \multirow{4}{*}{$>0.05$} \\
\hline 25-29.9 (overweight) & $42 \%$ & $15 \%$ & \\
\hline 30-34.9 (obese) & $38.60 \%$ & $55.60 \%$ & \\
\hline$>35$ (severely obese) & $9.70 \%$ & $7.40 \%$ & \\
\hline \multicolumn{4}{|l|}{ Comorbidities: } \\
\hline Diabetic & $16 \%$ & $16 \%$ & \\
\hline Hypertensive & $10 \%$ & $21 \%$ & \\
\hline Diabetic and Hypertensive & $30 \%$ & $42 \%$ & \\
\hline None & $44 \%$ & $21 \%$ & \\
\hline \multicolumn{4}{|l|}{ Smoking: } \\
\hline Smokers & $2.4 \%$ & $0 \%$ & \multirow{3}{*}{$>0.05$} \\
\hline Quit smoking & $7.3 \%$ & $0 \%$ & \\
\hline Not smokers & $90.3 \%$ & $100 \%$ & \\
\hline \multicolumn{4}{|l|}{ Physical activity: } \\
\hline Sedentary & $30 \%$ & $48 \%$ & \multirow{4}{*}{$<0.05$} \\
\hline Lightly active & $14 \%$ & $20 \%$ & \\
\hline Moderately active & $32 \%$ & $12 \%$ & \\
\hline Very active & $24 \%$ & $20 \%$ & \\
\hline
\end{tabular}

Classification of exercise levels are according to Harris Benedict Formula: Sedentary (little or no exercise), Lightly active (light exercise/sports 1-3 days/week), Moderately active (moderate exercise/sports 3-5 days/week), Very active (hard exercise/sports 6-7 days a week, Extra active (very hard exercise/sports and physical job or $2 x$ training). 


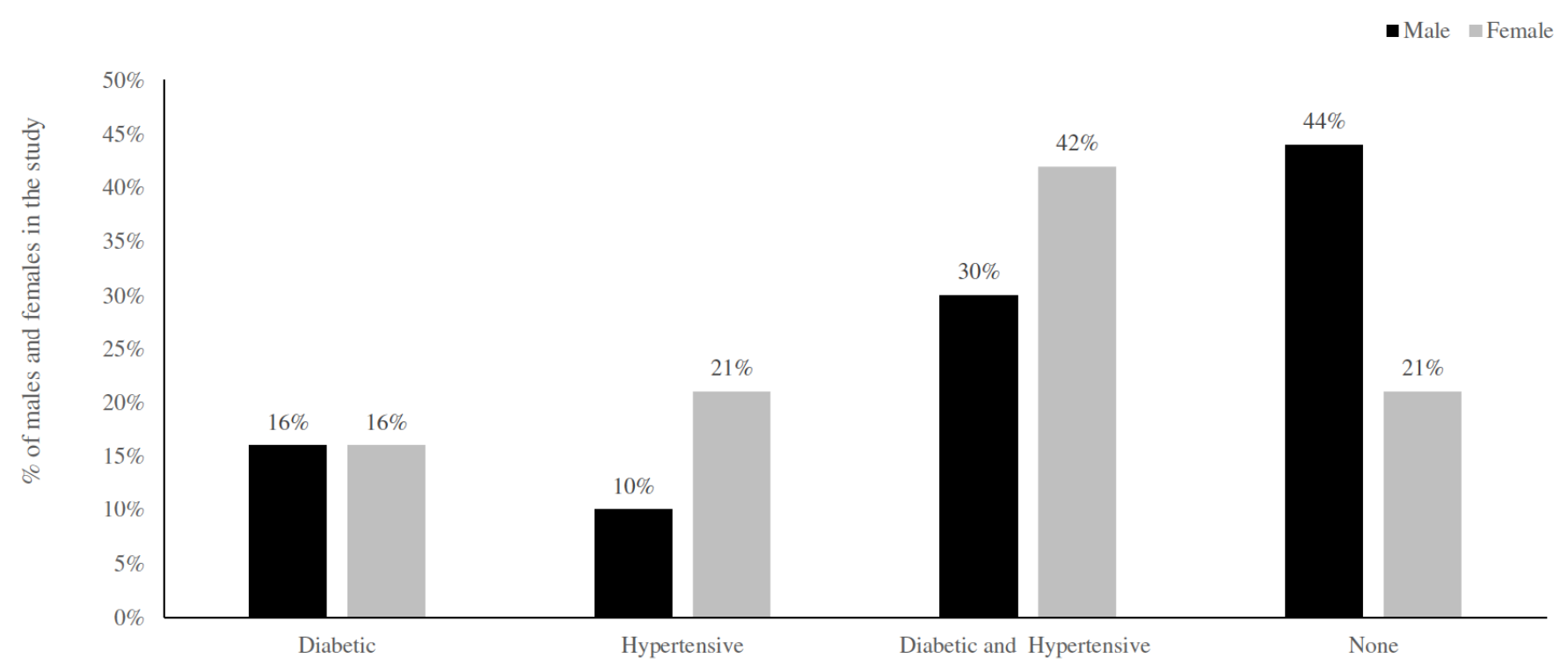

Figure 1: The percentage population of diabetic, hypertensive, diabetic and hypertensive and none (normal) among revascularized cardiac patients.

significantly $(P<0.05)$. A higher percentage of women $(48 \%)$ had a sedentary lifestyle as compared to men $(30 \%)$. Only $24 \%$ of males and $20 \%$ of women were physically very active. The study participants had poor nutritional knowledge and almost all didn't know about their daily energy and macronutrients requirements. Although all the participants had the opportunity to visit the Dieticians, only $48 \%$ of males and $56 \%$ of females consulted them for nutritional advice.

The data on the biochemical values of study participants was harvested from the SQUH's electronic health record system and is shown in Table 2 . The lowdensity lipoprotein-cholesterol (LDL-C), high-density lipoprotein-cholesterol (HDL-C) and C-reactive protein (CRP) values differed significantly between male and female patients. The values for LDL-C and HDL-C were within the normal range, whereas elevated levels for
CRP were observed. CRP is an inflammation marker as well as CVDs risk factors. Elevated levels were found in both genders and the values in males $(15.3 \pm$ $1.1 \mathrm{mmol} / \mathrm{L})$ were higher as compared to females $(7 \pm$ $0.5 \mathrm{mmol} / \mathrm{L})$ with no significant difference between them $(P>0.05)$. The average blood $\mathrm{Na}$ values in both males and females were within the normal range, whereas the glycated hemoglobin values (HbA1C) were a little above than the normal values indicating a higher risk probability of getting the diabetes. The data on the average daily energy and macronutrients intake is given in Table 3 . Males had significantly higher intake of energy (2694 vs 1603 kilocalories/day), protein ( 119 vs $70 \mathrm{~g} /$ day), carbohydrates ( 370 vs 225 $\mathrm{g} /$ day), and fats (82 vs $47 \mathrm{~g} /$ day), as compared to females. The proportionate contribution of energy from all the 3 macronutrients was within the recommended acceptable macronutrients distribution range (AMDR).

Table 2: Biochemical Indices of Male and Female Omani Revascularized Cardiac Patients

\begin{tabular}{|c|c|c|c|}
\hline Biochemical indices & Male $\mathbf{n}=\mathbf{4 1}$ & Female $\mathbf{n}=\mathbf{3 1}$ & Level of significance \\
\hline \hline $\mathrm{LDL}(\mathrm{mmol} / \mathrm{L})$ & $1.6 \pm 0.1$ & $2.0 \pm 0.1$ & $<0.05$ \\
\hline $\mathrm{HDL}(\mathrm{mmol} / \mathrm{L})$ & $1.0 \pm 0.1$ & $1.2 \pm 0.1$ & $<0.05$ \\
\hline $\mathrm{CRP}(\mathrm{mg} / \mathrm{L})$ & $9.3 \pm 1.1$ & $7.0 \pm 0.5$ & $<0.05$ \\
\hline $\mathrm{Na}(\mathrm{mmol} / \mathrm{L})$ & $138.6 \pm 3$ & $138.0 \pm 3.7$ & $\mathrm{NS}$ \\
\hline $\mathrm{HbA} 1 \mathrm{c}(\mathrm{mmol} / \mathrm{L})$ & $6.0 \pm 0.6$ & $6.1 \pm 0.6$ & $\mathrm{NS}$ \\
\hline
\end{tabular}

Data is presented as mean \pm standard deviation $(\mathrm{SD})$.

NS = non-significant.

Normal values and ranges according to SQUH's health tracker software program are:

1. LDL: (optimum < $2.59 \mathrm{mmol} / \mathrm{L}$, Near optimum 2.59-3.34 mmol/L, Borderline high: $3.37-4.12 \mathrm{mmol} / \mathrm{L}$, high: $>4.14 \mathrm{mmol} / \mathrm{L}$ ).

2. HDL: (desirable $>1.45$, Moderate $0.90-1.45$, low $<0.90 \mathrm{mmol} / \mathrm{L}$ ) for men and (desirable $>1.68$, Moderate $1.15-1.168$, low $<1.15 \mathrm{mmol} / \mathrm{L}$ for women).

3. C-reactive protein (CRP): $(0-5 \mathrm{mg} / \mathrm{L})$.

4. Na: $(135-145 \mathrm{mmol} / \mathrm{L})$.

5. HbA1c: $(4.5-5.7 \mathrm{mmol} / \mathrm{L})$. 
Table 3: Average Amounts of Daily Total Energy and Macronutrients Intake

\begin{tabular}{|c|c|c|c|}
\hline Daily Macronutrient intake & $\begin{array}{c}\text { Male } \\
(\mathbf{n}=\mathbf{4 1})\end{array}$ & $\begin{array}{c}\text { female } \\
(\mathbf{n}=\mathbf{3 1})\end{array}$ & level of significance \\
\hline \hline Total Calories (Kcal) & $2694 \pm 194$ & $1603 \pm 46$ & $<0.05$ \\
\hline Total protein (g) & $119 \pm 12$ & $70 \pm 10$ & $<0.05$ \\
\hline Total Carbohydrate (g) & $370 \pm 43$ & $225 \pm 17$ & $<0.05$ \\
\hline Total fat (g) & $82 \pm 4$ & $47 \pm 4$ & $<$ \\
\hline
\end{tabular}

Data is presented as mean \pm standard deviation (SD).

No significant $(P<0.05)$ difference was observed in the Omani Diet Score for males $(75.5 \pm 7.1)$ and females $(74.6 \pm 7.1)$. Some of the selected questions from the Omani Diet Score and the response of the study subject indicating their adherence to these factors assessed in Omani Diet Score are shown in Figures $\mathbf{2}$ and $\mathbf{3}$. The higher dietary scores indicated better adherence to healthy dietary intake patterns and food habits in these coronary revascularized patients. Eighty five percent of males and $74 \%$ of females were always taking their breakfast. Ninety percent of males and $78 \%$ of females were always taking 3 main meals daily. Higher percentage of females always ate their meals in small portions as compared to males. Fifty five percent of men and $64 \%$ of women were always eating fruits $\geq 2$ serving or $\geq 80 \mathrm{~g} /$ day. Sixty percent of males and $63 \%$ of the females were consuming vegetables $\geq$ 3 serving or $\geq 200 \mathrm{~g} /$ day. Eighty seven percent of males and $68 \%$ of females were always eating legumes/pulses $\geq 3$ servings or $\geq 150 \mathrm{~g} /$ week. The consumption of nuts, walnuts, peanuts was $\leq 1$ serving or $\leq 30 \mathrm{~g} /$ day in both males and females, which may be due to their dental problems as they couldn't chew this kind of solid food. Both males (90\%) and females $(92 \%)$ liked to eat fish $\geq 2$ serving or $100-150 \mathrm{~g} /$ week. The consumption of snacks between the meals varied among the participants and most of the participants were only taking ( $\geq 1$ serving) snacks sometimes. Most of the participants avoided drinking tea/coffee after meals ( $\geq 30$ minutes). Similarly, more than $90 \%$ of both males and females always avoided drinking soft drinks, avoided eating potato chips, crisps, salty snacks $(<1$ serving or $<30 \mathrm{~g}$ /day) and avoided eating highly flavored dishes with onions, garlic, or spices. Almost $80 \%$ tried to reduce the intake of red/processed meat ( $<1$ serving or $<80 \mathrm{~g} /$ day), butter or cream $(<1$ serving or $<12 \mathrm{~g} /$ day), fast foods ( $\leq 3$ servings or $250 \mathrm{~g}$ /week) and salt intake. More than $90 \%$ of males and females always watched their fat intake, whereas only $51 \%$ of males and $60 \%$ of females always watched

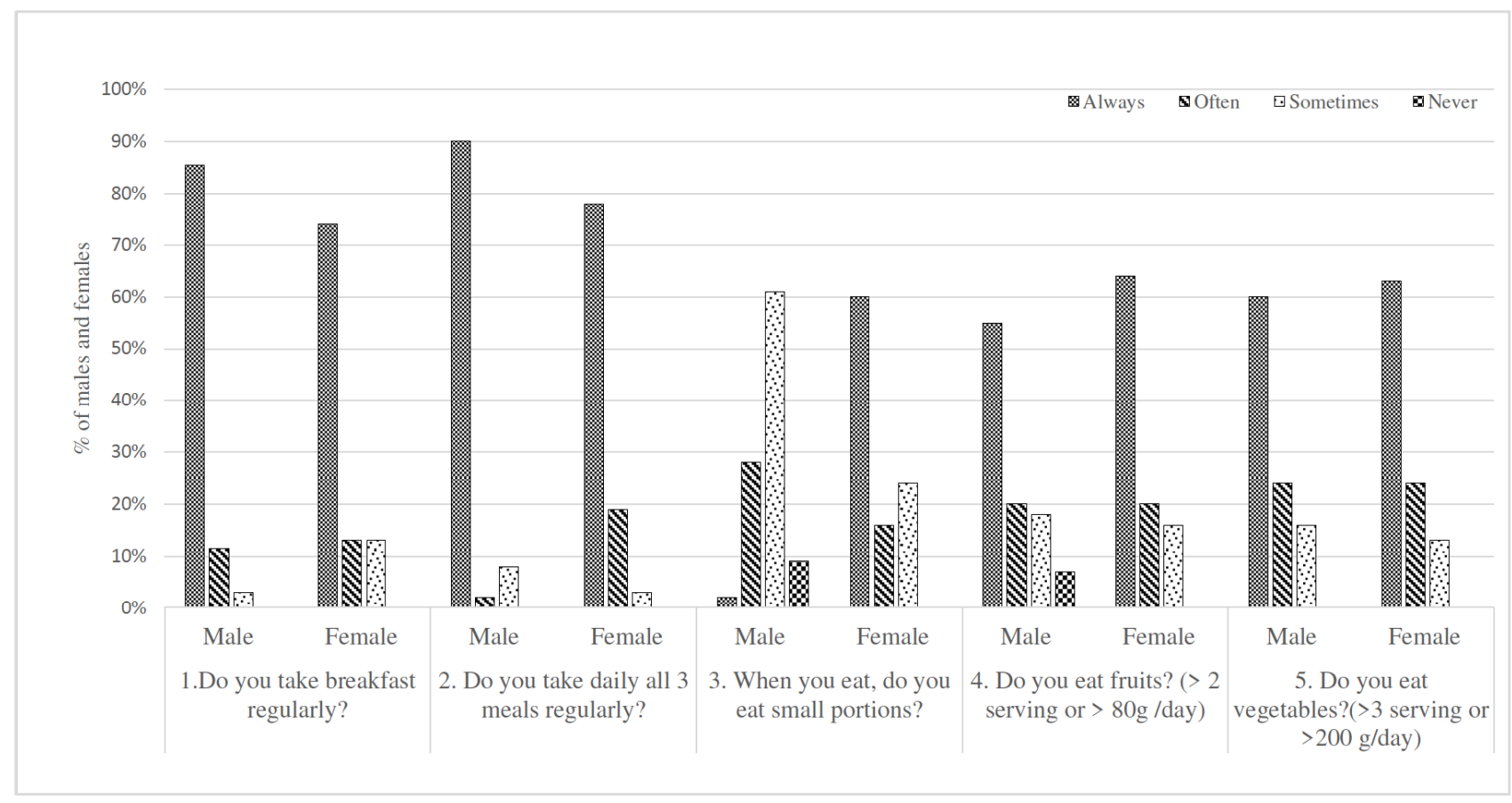

Figure 2: Adherence of the study subjects to some of the questions assessed in Omani Diet Score. 


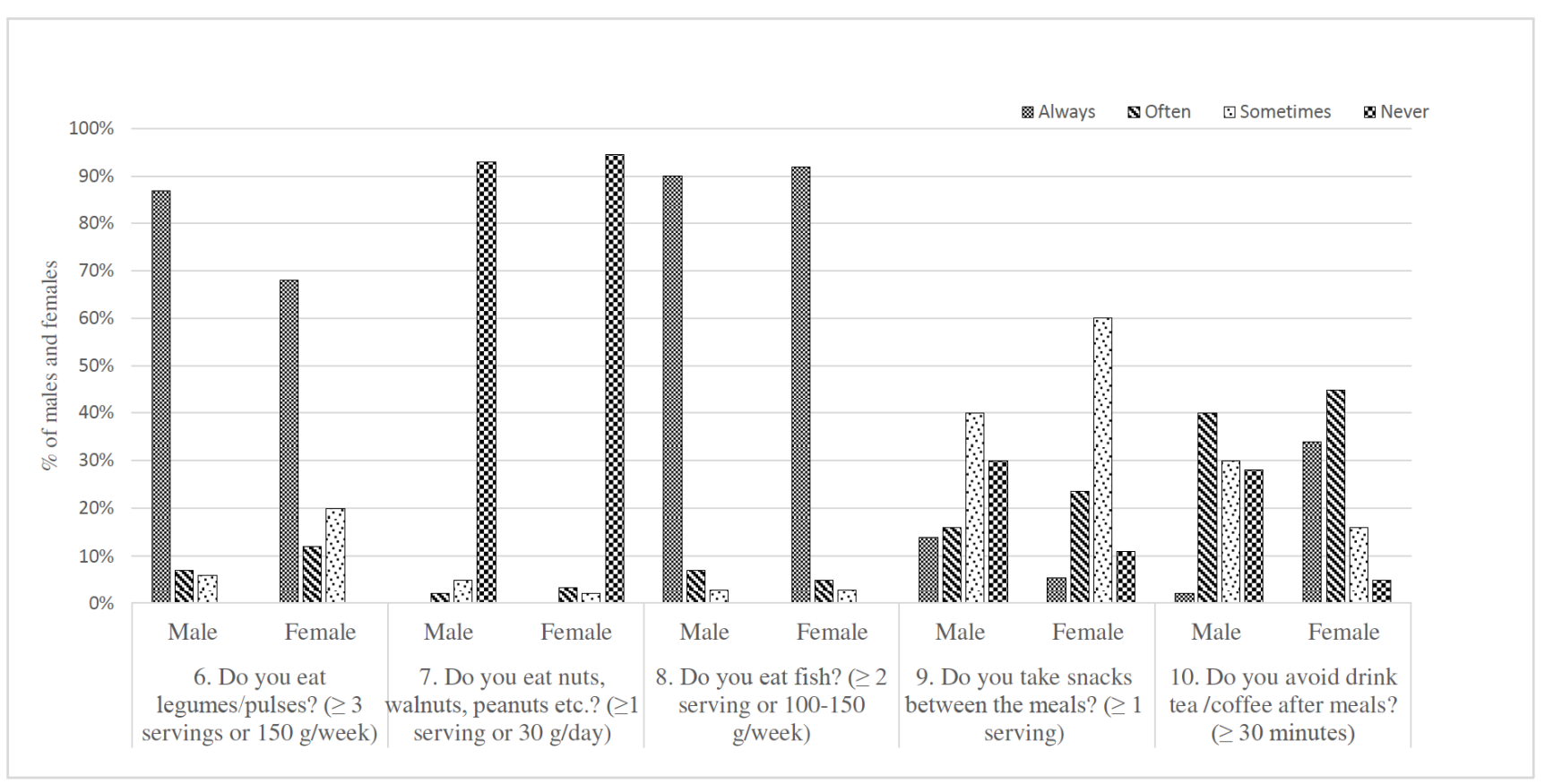

Figure 3: Adherence of the study subjects to some of the questions assessed in Omani Diet Score.

their carbohydrate intake. Most of the participants didn't watch their fiber intake regularly. Almost $100 \%$ of the study participants avoided taking vitamins and mineral supplements as well as protein supplements. More than $70 \%$ were using oil (corn, olive, canola, vegetable oils), instead of butter oil or ghee. Only $80 \%$ of males and $60 \%$ of females sometimes searched for nutrition information. Almost $80 \%$ of males and $40 \%$ of females followed the recommended dietary guidelines about healthy diets. Almost $52 \%$ of females never followed any diet plans such as low fat, low carbohydrate, or vegetarian diet.

\section{DISCUSSION}

The study evaluated the role of different lifestyle and dietary modifications on the biomarkers of plaque recurrence in revascularized Omani patients. Most of the cardiac patients had very low educational level as $36 \%$ of males and $76 \%$ of females had less than primary level of education. This may be one of the main reasons why these patients had little knowledge about the diet and disease relationship, which may be regarded as a risk factor for the cardiac diseases. The knowledge about heart diseases and awareness about their risk factors has been shown to have positive associations with health promotion behaviours [39]. The low educational level and limited knowledge about the CVDs in our study participants explains the limitations in their ability to effectively follow the preventative practices and lifestyle and dietary modifications. There is a need to develop and implement the appropriate educational programs to increase awareness about the role of lifestyle and dietary modifiable risk factors in the prevention of CVDs in Oman. The risk of heart disease increases with age and the use of statins in the primary prevention of heart disease in elderly people should therefore be based on good clinical judgement with respect to comorbidities, polypharmacy, and possible adverse effects (Reiner, 2014). Another risk factor in the studied participants was the elevated BMI levels, as only $9.7 \%$ of males and $22 \%$ of females had normal BMI. Overweight and obesity are linked to hypertension, diabetes, elevated levels of blood LDL-C, CRP and other CVDs risk biomarkers and constitute a major risk factor for coronary heart diseases [40]. Most of the cardiac patients were either diabetic, hypertensive or both diabetic and hypertensive and only $44 \%$ of males and $21 \%$ of females were neither diabetic nor hypertensive. Diabetes and hypertension were the major risk factors of CVDs in the studied participants. Our findings are in line with the results of a previous study, which revealed that $54.1 \%$ of Omani patients presented for coronary artery bypass surgery were found to be diabetics [41]. The prevalence of hypertension, obesity and dyslipidemia in Omani type-2 diabetic patients has been reported to be $56.3 \%$, $39.0 \%, 77.3 \%$, respectively, which indicates the presence of cardiovascular disease risk factor in type-2 diabetic patients [42]. Hypertensive heart diseases are the main form of all CVDs in Omani population and account for $71 \%$ of total CVDs [14]. Smoking is considered as one of the risk factor for the 
cardiometabolic events and quitting smoking is linked to decreased risk of myocardial infarction as compared to persistent smokers [12]. Smoking was not prevalent in the studied Omani participants as only $2.4 \%$ of males were smokers and $8 \%$ of them quitted smoking after their surgeries. So, it was not considered as a causative factor of CVDs in this studied population. Overall smoking is not very common in Omani population and the highest frequency of smoking (11.4\%) was reported in people between the ages 40 49 years [43]. However, it's important to pay attention on younger generation to combat smoking as more than $10 \%$ of Omani youth (13-15 years of age) use tobacco products and another $12 \%$ are passive smokers, which may increase their risk of developing CVDs at later stage [14, 44]. Being physically inactive was a common risk factor among the studied participants as $48 \%$ of women and $30 \%$ of men had a sedentary lifestyle. Regular physical activity has positive impact on metabolic syndrome, insulin sensitivity, cardiovascular disease risk, inflammatory biomarkers and all-cause mortality and can therefore help to lessen the burden of disease [45-47]. The study participants had poor nutritional knowledge and didn't have any idea about their daily energy and nutrient requirements. They had the opportunity to visit the Dieticians but only $48 \%$ of males and $56 \%$ of females consulted them for nutritional advice. This may be due to their low educational level and necessitates the need for developing the educational programs to increase awareness about the risk factors in the prevention of cardiovascular diseases in Oman.

The elevated level of LDL-C in blood is linked to an increased risk of cardiovascular diseases. Efforts to lower its levels are therefore important in the management of CVDs as statin therapy is sometimes insufficient to optimally reduce the LDL-C below target values [48]. The average LDL-C values were optimal in both genders and that could be the effect of medication (statin) or lower fat diet with fat consumption of $25 \%$ $35 \%$ of total calories. In addition to this $24 \%$ of males and $20 \%$ of women were physically very active, and $32 \%$ male and $12 \%$ females were moderately active. This also indicates their adherence to lifestyle modifications. More women (48\%) had sedentary lifestyle and therefore need counselling on physical activity. There is evidence that lowering of abnormally high LDL-C levels can be achieved by diet and exercise and therefore counselling on dietary and lifestyle modifications can be effective in achieving the targets [49]. The average HDL-C values of the study subjects was within the moderate range according to the classification of SQUH's health tracker software program. Quitting smoking has also been shown to increase the HDL-C levels and our study participants either didn't smoke or quitted smoking after the $\mathrm{PCl}$ [50]. The CRP is an inflammatory biomarker and CVDs risk factor. The CRP values were high in our study subjects, which can occur in post $\mathrm{PCl}$ and $\mathrm{CABG}$ patients and indicate poor diet quality and nonadherence of lifestyle modifications [25, 51]. The lifestyle modifications such as healthy eating and smoking cessation are therefore regarded as the foundation of optimal medical nutrition therapy[30]. The average blood $\mathrm{Na}$ values in both males and females were within the normal range, whereas the glycated hemoglobin values $(\mathrm{HbA} 1 \mathrm{C})$ were a little above than the normal values but were within the target range for the diabetic cardiac patients [52]. Sodium intake is associated with changes in circulating blood metabolites and an imbalance in sodium levels indicate hypertension or kidney malfunction [53]. Achieving WHO targets levels for dietary intake is essential in the management of cardiometabolic risk factors [54, 55]. Glycated hemoglobin is an indicator of long-term glycemic control, and its elevated levels together with raised blood pressure and cholesterol, can increase the risk of complications in CVDs [56].

Males had significantly higher intake of energy (2694 vs 1603 kilocalories/day), protein (119 vs 70 g/day), carbohydrates ( 370 vs $225 \mathrm{~g} /$ day), and fats (82 vs $47 \mathrm{~g} /$ day), as compared to females, which is normal according to their physiological needs. Intake of all 3 macronutrients, protein, carbohydrate and fat was within the recommended dietary allowances. Similarly, the proportionate contribution of energy from macronutrients was within the recommended acceptable macronutrients distribution ranges (AMDR) [57]. Some studies suggest that low carbohydrate diets may decrease the overall risk of CVDs by reducing the weight gain and obesity and improving the cardiometabolic biomarkers in blood [58]. However, further clinical evidence is required to support it [59]. A low-carbohydrate diet is defined as the consumption of $30-130 \mathrm{~g}$ of carbohydrates per day or less than $45 \%$ of total calories/day consumed from carbohydrates and may contain low levels of saturated fat, thereby encourages a greater weight loss as compared to lowfat diets [60]. The adherence to Mediterranean style diet containing high-quality carbohydrates from whole grains has been reported to be associated with lower risk of CVDs [61].

To assess the diet quality and eating patterns of Omani population, an Omani Diet Score was 
developed and used in this study to evaluate how healthy the dietary intake of the study participants was. No significant differences were observed in the Omani Diet Score for males $(75.5 \pm 7.1)$ and females $(74.6 \pm$ 7.1). The higher dietary scores indicated better adherence to healthy dietary intake patterns and eating habits in these coronary revascularized patients. It was observed that $85 \%$ of males and $74 \%$ of females were always taking their breakfast. Ninety percent of males and $78 \%$ of females were always taking 3 main meals daily. More females ate their meals in small portions as compared to males, which explains the higher daily intake of total energy, protein, carbohydrates and fat in males. Fifty five percent of men and $64 \%$ of women were always eating fruits $\geq 2$ serving or $\geq 80 \mathrm{~g} /$ day. More than $60 \%$ of the study participants were consuming vegetables $\geq 3$ serving or $\geq 200 \mathrm{~g} /$ day and avoided soft drinks and junk foods. Eighty seven percent of males and $68 \%$ of females were always eating legumes/pulses $\geq 3$ servings or $\geq 150 \mathrm{~g} /$ week. Almost all the patients were prescribed statin therapy and some of them showed gastroesophageal reflux disease (GERD) as a side effect of medication as it is linked to higher probabilities of being detected with esophagitis and gastroesophageal reflux disease [62]. In addition to this, obesity has also been linked with increased symptoms of GERD and requires special attention in cardiac obese patients [63].

\section{CONCLUSION}

Diet and physical activity are the main factors linked to increased risk of CVDs and are easier to modify with the introduction of educational and behavioural change programs $[64,65]$. The results of the present study suggest that dietary and lifestyle modifications such as physical activity, weight reduction, healthy eating pattern and smoking cessation can have positive impact in the secondary prevention of biomarkers of plaque recurrence in Omani coronary revascularized patients. Behavioral counseling to promote healthy eating patterns, physical activity and smoking cessation will therefore be very helpful in this regard. Welldesigned randomized control trials are required to further explore the efficacy of such modifications in the secondary prevention of biomarkers of plaque recurrence in Omani coronary revascularized patients.

\section{ACKNOWLEDGEMENTS}

We are thankful to the study participant for their commitment, patience and cooperation during the study. We would also like to thank the staff of the Cardiology Clinic, Sultan Qaboos University Hospital for their help and cooperation. Thanks, are also due to Dr. Michel R. G. Claereboudt for his help in the statistical analysis of the data.

\section{CONFLICTS OF INTEREST}

The authors declare no conflict of interest.

\section{ETHICAL APPROVAL}

The ethical approval of the study was obtained from the Medical Ethics Committee of College of Medicine and Health Sciences, Sultan Qaboos University (Reference No. SQU-EC/250/17; MREC \# 1629, dated $7^{\text {th }}$ January 2018).

\section{REFERNCES}

[1] World Health Organization, WHO. Cardiovascular Dieases Key Facts. News-room, World Health Organization: 2017.

[2] Benjamin Emelia J, Muntner P, Alonso A, Bittencourt Marcio S, Callaway Clifton W, Carson April P, et al. Heart Disease and Stroke Statistics-2019 Update: A Report From the American Heart Association. Circulation 2019; 139(10): e56e528.

[3] Al Rasadi K, Almahmeed W, AlHabib KF, Abifadel M, Farhan HA, AlSifri S, et al. Dyslipidaemia in the Middle East: Current status and a call for action. Atherosclerosis 2016; 252: 182-7. https://doi.org/10.1016/j.atherosclerosis.2016.07.925

[4] Ammouri AA, Tailakh A, Isac C, Kamanyire JK, Muliira J, Balachandran S. Knowledge of Coronary Heart Disease Risk Factors among a Community Sample in Oman : Pilot study. Sultan Qaboos University Medical Journal 2016; 16(2): 18996.

https://doi.org/10.18295/squmj.2016.16.02.009

[5] Khalid F, Sulaiman K, Al-Motarreb A, Almahmeed W, Asaad $\mathrm{N}$, Amin $\mathrm{H}$, et al. Baseline characteristics, management practices, and long-term outcomes of Middle Eastern patients in the Second Gulf Registry of Acute Coronary Events (Gulf RACE-2). Annals of Saudi medicine 2012; 32: 9-18. https://doi.org/10.5144/0256-4947.2012.9

[6] Alhabib KF, Sulaiman K, Al-Motarreb A, Almahmeed W, Asaad $\mathrm{N}$, Amin $\mathrm{H}$, et al. Baseline characteristics, management practices, and long-term outcomes of Middle Eastern patients in the Second Gulf Registry of Acute Coronary Events (Gulf RACE-2). Annals of Saudi medicine 2012; 32(1): 9-18.

https://doi.org/10.5144/0256-4947.2012.9

[7] Dhingra R, Vasan RS. Biomarkers in cardiovascular disease: Statistical assessment and section on key novel heart failure biomarkers. Trends in cardiovascular medicine 2017; 27(2): 123-33.

https://doi.org/10.1016/j.tcm.2016.07.005

[8] Hage C, Michaelsson E, Linde C, Donal E, Daubert JC, Gan LM, et al. Inflammatory Biomarkers Predict Heart Failure Severity and Prognosis in Patients With Heart Failure With Preserved Ejection Fraction: A Holistic Proteomic Approach. Circulation Cardiovascular genetics 2017; 10(1). https://doi.org/10.1161/CIRCGENETICS.116.001633

[9] Al Rawahi AH, Lee P, Al Anqoudi ZAM, Al Busaidi A, Al Rabaani M, Al Mahrouqi $\mathrm{F}$, et al. Cardiovascular Disease Incidence and Risk Factor Patterns among Omanis with Type 2 Diabetes: A Retrospective Cohort Study. Oman Medical Journal 2017; 32(2): 106-14.

https://doi.org/10.5001/omj.2017.20 
[10] Pieris RR, Al-Sabti HA, Al-Abri QSA, Rizvi SGA. Prevalence Pattern of Risk Factors for Coronary Artery Disease among Patients Presenting for Coronary Artery Bypass Grafting in Oman. Oman medical journal 2014; 29(3): 203-7. https://doi.org/10.5001/omj.2014.50

[11] Bersch-Ferreira AC, Sampaio GR, Gehringer MO, RossFernandes MB, Kovacs C, Alves $\mathrm{R}$, et al. Association between polyunsaturated fatty acids and inflammatory markers in patients in secondary prevention of cardiovascular disease. Nutrition (Burbank, Los Angeles County, Calif) 2017; 37: 30-6.

https://doi.org/10.1016/j.nut.2016.12.006

[12] Chow CK, Jolly S, Rao-Melacini P, Fox KA, Anand SS, Yusuf $\mathrm{S}$. Association of diet, exercise, and smoking modification with risk of early cardiovascular events after acute coronary syndromes. Circulation 2010; 121(6): 750-8. https://doi.org/10.1161/CIRCULATIONAHA.109.891523

[13] Chow CK, Jolly S, Rao-Melacini P, Fox KAA, Anand SS, Yusuf S. Association of Diet, Exercise, and Smoking Modification With Risk of Early Cardiovascular Events After Acute Coronary Syndromes. Circulation 2010; 121(6): 750-8. https://doi.org/10.1161/CIRCULATIONAHA.109.891523

[14] Al-Mawali A. Non-Communicable Diseases: Shining a Light on Cardiovascular Disease, Oman's Biggest Killer. Oman Medical Journal 2015; 30(4): 227-8.

https://doi.org/10.5001/omj.2015.47

[15] Bansilal S, Castellano JM, Fuster V. Global burden of CVD: focus on secondary prevention of cardiovascular disease. International journal of cardiology 2015; 201: S1-S7. https://doi.org/10.1016/S0167-5273(15)31026-3

[16] Ghosal S, Sinha B. Secondary cvd prevention-Lipid modification strategies: A critical analysis. Diabetes \& Metabolic Syndrome: Clinical Research \& Reviews 2017; 11(Supplement 1): S187-S93.

https://doi.org/10.1016/j.dsx.2016.12.030

[17] Grundy SM, Cleeman JI, Merz CN, Brewer HB, Jr., Clark LT, Hunninghake DB, et al. Implications of recent clinical trials for the National Cholesterol Education Program Adult Treatment Panel III guidelines. Circulation 2004; 110(2): 227-39. https://doi.org/10.1161/01.CIR.0000133317.49796.0E

[18] Bansal M, Chandra KS. The 2013 American College of Cardiology (ACC)/American Heart Association (AHA) guidelines for cholesterol management and for cardiovascular risk stratification: a reappraisal. Indian heart journal 2014; 66(1): 1-4.

https://doi.org/10.1016/j.ihj.2014.01.003

[19] Hambrecht R, Walther C, Mobius-Winkler S, Gielen S, Linke $\mathrm{A}$, Conradi $\mathrm{K}$, et al. Percutaneous coronary angioplasty compared with exercise training in patients with stable coronary artery disease: a randomized trial. Circulation 2004; 109(11): 1371-8. https://doi.org/10.1161/01.CIR.0000121360.31954.1F

[20] Parsons C, Agasthi P, Mookadam F, Arsanjani R. Reversal of coronary atherosclerosis: Role of life style and medical management. Trends in Cardiovascular Medicine 2018. https://doi.org/10.1016/j.tcm.2018.05.002

[21] Ogawa K, Tanaka T, Nagoshi T, Sekiyama H, Arase S, Minai $\mathrm{K}$, et $\mathrm{al}$. Increase in the oxidised low-density lipoprotein level by smoking and the possible inhibitory effect of statin therapy in patients with cardiovascular disease: a retrospective study. BMJ open 2015; 5(1): e005455. https://doi.org/10.1136/bmjopen-2014-005455

[22] Vallejo-Vaz AJ, Robertson M, Catapano AL, Watts GF, Kastelein JJ, Packard CJ, et al. Low-Density Lipoprotein Cholesterol Lowering for the Primary Prevention of Cardiovascular Disease Among Men With Primary Elevations of Low-Density Lipoprotein Cholesterol Levels of $190 \mathrm{mg} / \mathrm{dL}$ or Above. Circulation 2017; 136(20): 1878-91.

https://doi.org/10.1161/CIRCULATIONAHA.117.027966

[23] Wadhera RK, Steen DL, Khan I, Giugliano RP, Foody JM. A review of low-density lipoprotein cholesterol, treatment strategies, and its impact on cardiovascular disease morbidity and mortality. Journal of clinical lipidology 2016; 10(3): 472-89. https://doi.org/10.1016/j.jacl.2015.11.010

[24] Chiavaroli L, Nishi SK, Khan TA, Braunstein CR, Glenn AJ, Mejia SB, et al. Portfolio Dietary Pattern and Cardiovascular Disease: A Systematic Review and Meta-analysis of Controlled Trials. Prog Cardiovasc Dis 2018; 61(1): 43-53. https://doi.org/10.1016/j.pcad.2018.05.004

[25] Abbasalizad Farhangi M, Najafi M. Empirically developed dietary inflammatory potential (EDIP) in patients candidate for coronary artery bypass grafting surgery (CABG): Association with metabolic parameters, dietary antioxidant quality score and dietary phytochemical index. PloS one 2018; 13(12): e0208711.

https://doi.org/10.1371/journal.pone.0208711

[26] Chan R, Yau F, Yu B, Woo J. The Role of Dietary Patterns in the Contribution of Cardiorespiratory Fitness in CommunityDwelling Older Chinese Adults in Hong Kong. Journal of the American Medical Directors Association 2019.

https://doi.org/10.1016/j.jamda.2018.12.009

[27] Verma P, Srivastava R, Jain D. Association of lifestyle risk factors with metabolic syndrome components: A crosssectional study in Eastern India. International journal of preventive medicine 2018; 9(1): 6 .

https://doi.org/10.4103/ijpvm.IJPVM 23617

[28] Pagidipati NJ, Navar AM, Pieper KS, Green JB, Bethel MA, Armstrong PW, et al. Secondary Prevention of Cardiovascular Disease in Patients With Type 2 Diabetes Mellitus. International Insights From the TECOS Trial (Trial Evaluating Cardiovascular Outcomes With Sitagliptin) 2017; 136(13): 1193-203. https://doi.org/10.1161/CIRCULATIONAHA.117.027252

[29] Garshick MS, Vaidean GD, Vani A, Underberg JA, Newman JD, Berger JS, et al. Cardiovascular Risk Factor Control and Lifestyle Factors in Young to Middle-Aged Adults with Newly Diagnosed Obstructive Coronary Artery Disease. Cardiology 2019; 142(2): 83-90.

https://doi.org/10.1159/000498891

[30] Paruchuri V, Gaztanaga J, Rambhujun V, Smith R, Farkouh ME. Food as Medicine for Secondary Prevention of Cardiovascular Events Following an Acute Coronary Syndrome. Cardiovasc Drugs Ther 2018; 32(6): 611-6. https://doi.org/10.1007/s10557-018-6798-6

[31] Malambo P, Kengne AP, De Villiers A, Lambert EV, Puoane T. Built Environment, Selected Risk Factors and Major Cardiovascular Disease Outcomes: A Systematic Review. PloS one 2016; 11(11): e0166846. https://doi.org/10.1371/journal.pone.0166846

[32] Buttar HS, Li T, Ravi N. Prevention of cardiovascular diseases: Role of exercise, dietary interventions, obesity and smoking cessation. Experimental and clinical cardiology 2005; 10(4): 229-49.

[33] Daubenmier JJ, Weidner G, Sumner MD, Mendell N, MerrittWorden T, Studley J, et al. The contribution of changes in diet, exercise, and stress management to changes in coronary risk in women and men in the multisite cardiac lifestyle intervention program. Annals of behavioral medicine: a publication of the Society of Behavioral Medicine 2007; 33(1): 57-68. https://doi.org/10.1207/s15324796abm3301 7

[34] Brinks J, Fowler A, Franklin BA, Dulai J. Lifestyle Modification in Secondary Prevention: Beyond Pharmacotherapy. American Journal of Lifestyle Medicine 2016; 11(2): 137-52. https://doi.org/10.1177/1559827616651402

[35] Sadiq MAS, Amanat Ali, Mostafa I. Waly, Hilal Nasser Mohammed Al-Busaidi, Al-Hamrashdi SNA. Impact of Dietary and Lifestyle Modifications on the Secondary Prevention of Coronary Heart Disease in Omani Percutaneous Coronary 
Intervention Patients. Canadian Journal of Clinical Nutrition 2019; 7(1): 46-65.

https://doi.org/10.14206/canad.j.clin.nutr.2019.01.05

[36] Ali A, Al-Belushi BS, Waly MI, Al-Moundhri M, Burney IA. Dietary and lifestyle factors and risk of non-hodgkin's lymphoma in Oman. Asian Pacific journal of cancer prevention : APJCP 2013; 14(2): 841-8.

https://doi.org/10.7314/APJCP.2013.14.2.841

[37] Medina-Remon A, Kirwan R, Lamuela-Raventos RM, Estruch R. Dietary patterns and the risk of obesity, type 2 diabetes mellitus, cardiovascular diseases, asthma, and neurodegenerative diseases. Critical reviews in food science and nutrition 2018; 58(2): 262-96.

https://doi.org/10.1080/10408398.2016.1158690

[38] Schwingshackl L, Hoffmann G. Diet quality as assessed by the Healthy Eating Index, the Alternate Healthy Eating Index, the Dietary Approaches to Stop Hypertension score, and health outcomes: a systematic review and meta-analysis of cohort studies. Journal of the Academy of Nutrition and Dietetics 2015; 115(5): 780-800.e5.

https://doi.org/10.1016/j.jand.2014.12.009

[39] Ammouri AA, Abu Raddaha AH, Tailakh A, Kamanyire J, Achora S, Isac C. Risk Knowledge and Awareness of Coronary Heart Disease, and Health Promotion Behaviors Among Adults in Oman. Res Theory Nurs Pract 2018; 32(1): 46-62.

https://doi.org/10.1891/1541-6577.32.1.46

[40] Lu Y, Hajifathalian K, Rimm EB, Ezzati M, Danaei G. Mediators of the effect of body mass index on coronary heart disease: decomposing direct and indirect effects. Epidemiology (Cambridge, Mass) 2015; 26(2): 153-62. https://doi.org/10.1097/EDE.0000000000000234

[41] Alrawahi AH, Lee P. Validation of the cardiovascular risk model developed for Omanis with type 2 diabetes. Diabetes \& Metabolic Syndrome: Clinical Research \& Reviews 2018; 12(3): 387-91.

[42] Al-Rawahi A, Lee P. Applicability of the Existing CVD Risk Assessment Tools to Type II Diabetics in Oman: A Review. Oman Medical Journal 2015; 30(5): 315-9.

https://doi.org/10.1016/j.dsx.2018.01.004

[43] Al Riyami AA, Afifi M. Smoking in Oman: prevalence and characteristics of smokers. Eastern Mediterranean health journal $=$ La revue de sante de la Mediterranee orientale $=$ alMajallah al-sihhiyah li-sharq al-mutawassit 2004; 10(4-5): 600-9.

https://doi.org/10.5001/omj.2015.65

[44] Alanbaei M, Zubaid M, Al-Mallah MH, Rashed WA, Shehab A, Al-Lawati J, et al. Impact of Diabetes and Smoking Epidemic in the Middle East on the Presentation With Acute Coronary Syndrome in Very Young Patients. Angiology 2011; 63(1): 48-54. https://doi.org/10.1177/0003319711406255

[45] Alves AJ, Viana JL, Cavalcante SL, Oliveira NL, Duarte JA, Mota J, et al. Physical activity in primary and secondary prevention of cardiovascular disease: Overview updated. World Journal of Cardiology 2016; 8(10): 575-83. https://doi.org/10.4330/wjc.v8.i10.575

[46] Després J-P. Physical Activity, Sedentary Behaviours, and Cardiovascular Health: When Will Cardiorespiratory Fitness Become a Vital Sign? Canadian Journal of Cardiology 2016; 32(4): 505-13.

https://doi.org/10.1016/j.cjca.2015.12.006

[47] Winzer EB, Woitek F, Linke A. Physical Activity in the Prevention and Treatment of Coronary Artery Disease. Journal of the American Heart Association 2018; 7(4). https://doi.org/10.1161/JAHA.117.007725

[48] Krähenbühl S, Pavik-Mezzour I, von Eckardstein A. Unmet Needs in LDL-C Lowering: When Statins Won't Do! Drugs 2016; 76(12): 1175-90.

https://doi.org/10.1007/s40265-016-0613-0
[49] Sialvera TE, Papadopoulou A, Efstathiou SP, Trautwein EA, Ras RT, Kollia N, et al. Structured advice provided by a dietitian increases adherence of consumers to diet and lifestyle changes and lowers blood low-density lipoprotein (LDL)-cholesterol: the Increasing Adherence of Consumers to Diet \& Lifestyle Changes to Lower (LDL) Cholesterol (ACT) randomised controlled trial. Journal of Human Nutrition and Dietetics 2018; 31(2): 197-208.

https://doi.org/10.1111/jhn.12508

[50] Forey BA, Fry JS, Lee PN, Thornton AJ, Coombs KJ. The effect of quitting smoking on HDL-cholesterol - a review based on within-subject changes. Biomarker Research 2013; 1: 26. https://doi.org/10.1186/2050-7771-1-26

[51] Chan RSM, Yu BWM, Leung J, Lee JSW, Auyeung TW, Kwok $\mathrm{T}$, et al. How Dietary Patterns are Related to Inflammaging and Mortality in Community-Dwelling Older Chinese Adults in Hong Kong - A Prospective Analysis. The journal of nutrition, health \& aging 2019; 23(2): 181-94. https://doi.org/10.1007/s12603-018-1143-0

[52] Bridgwood B, Lager KE, Mistri AK, Khunti K, Wilson AD, Modi $P$. Interventions for improving modifiable risk factor control in the secondary prevention of stroke. The Cochrane database of systematic reviews 2018; 5(5): CD009103-CD. https://doi.org/10.1002/14651858.CD009103.pub3

[53] Derkach A, Sampson J, Joseph J, Playdon MC, StolzenbergSolomon RZ. Effects of dietary sodium on metabolites: the Dietary Approaches to Stop Hypertension (DASH)-Sodium Feeding Study. Am J Clin Nutr 2017. https://doi.org/10.3945/ajcn.116.150136

[54] Goff LM, Huang P, Silva MJ, Bordoli C, Enayat EZ, Molaodi $\mathrm{OR}$, et al. Associations of dietary intake with cardiometabolic risk in a multi-ethnic cohort: a longitudinal analysis of the Determinants of Adolescence, now young Adults, Social wellbeing and Health (DASH) study. The British journal of nutrition 2019: 1-25. https://doi.org/10.1017/S0007114519000291

[55] Eyles H, Shields E, Webster J, Ni Mhurchu C. Achieving the WHO sodium target: estimation of reductions required in the sodium content of packaged foods and other sources of dietary sodium. Am J Clin Nutr 2016; 104(2): 470-9. https://doi.org/10.3945/ajcn.115.125146

[56] Wan EYF, Fung CSC, Wong CKH, Chin WY, Lam CLK. Association of Hemoglobin A1c Levels With Cardiovascular Disease and Mortality in Chinese Patients With Diabetes. Journal of the American College of Cardiology 2016; 67(4): 456-8. https://doi.org/10.1016/j.jacc.2015.11.020

[57] Yetley EA, MacFarlane AJ, Greene-Finestone LS, Garza C Ard JD, Atkinson SA, et al. Options for basing Dietary Reference Intakes (DRIs) on chronic disease endpoints: report from a joint US-/Canadian-sponsored working group. The American journal of clinical nutrition 2017; 105(1): 249S$85 \mathrm{~S}$. https://doi.org/10.3945/ajen.116.139097

[58] Hu T, Bazzano LA. The low-carbohydrate diet and cardiovascular risk factors: evidence from epidemiologic studies. Nutrition, metabolism, and cardiovascular diseases : NMCD 2014; 24(4): 337-43. https://doi.org/10.1016/j.numecd.2013.12.008

[59] Naude CE, Schoonees A, Senekal M, Young T, Garner P, Volmink J. Low carbohydrate versus isoenergetic balanced diets for reducing weight and cardiovascular risk: a systematic review and meta-analysis. PloS one 2014; 9(7): e100652-e. https://doi.org/10.1371/journal.pone.0100652

[60] Eilat-Adar S, Sinai T, Yosefy C, Henkin Y. Nutritional Recommendations for Cardiovascular Disease Prevention. Nutrients 2013; 5(9): 3646-83. https://doi.org/10.3390/nu5093646 
[61] D'Alessandro A, De Pergola G. The Mediterranean Diet: its definition and evaluation of a priori dietary indexes in primary cardiovascular prevention. International journal of food sciences and nutrition 2018: 1-13.

[62] Smith I, Schmidt R, Halm EA, Mansi IA. Do Statins Increase the Risk of Esophageal Conditions? Findings from Four Propensity Score-Matched Analyses. Clin Drug Investig 2018; 38(2): 135-46 https://doi.org/10.1007/s40261-017-0589-x

[63] Nau P, Jackson HT, Aryaie A, Ibele A, Shouhed D, Lo Menzo $\mathrm{E}$, et al. Surgical management of gastroesophageal reflux disease in the obese patient. Surgical endoscopy 2019. https://doi.org/10.1007/s00464-019-07231-w
[64] Grossman DC, Bibbins-Domingo K, Curry SJ, Barry MJ, Davidson KW, Doubeni CA, et al. Behavioral Counseling to Promote a Healthful Diet and Physical Activity for Cardiovascular Disease Prevention in Adults Without Cardiovascular Risk Factors: US Preventive Services Task Force Recommendation Statement. Jama 2017; 318(2): 16774.

https://doi.org/10.1001/jama.2017.7171

[65] Ribeiro RV, Hirani V, Senior AM, Gosby AK, Cumming RG, Blyth FM, et al. Diet quality and its implications on the cardiometabolic, physical and general health of older men: the Concord Health and Ageing in Men Project (CHAMP). The British journal of nutrition 2017; 118(2): 130-43. https://doi.org/10.1017/S0007114517001738

Received on 07-01-2020

Accepted on 08-02-2020

Published on 12-03-2020

DOI: https://doi.org/10.29169/1927-5951.2020.10.02.3

(C) 2020 Ali et al.; Licensee SET Publisher.

This is an open access article licensed under the terms of the Creative Commons Attribution Non-Commercial License (http://creativecommons.org/licenses/by-nc/3.0/) which permits unrestricted, non-commercial use, distribution and reproduction in any medium, provided the work is properly cited. 